\title{
Intercultural Language Teaching Practice in EFL Classroom China--College English Instruction Based on Film The Proposal
}

\author{
Fang Liu ${ }^{1,2}$ \\ ${ }^{1}$ School of Foreign Languages, Guilin University of Electronic Technology, Guilin, Guangxi, China \\ ${ }^{2}$ College of Education \& Human Development, University of North Dakota, USA \\ Correspondence: Fang Liu, No.1 Jinji Road, School of Foreign Languages, Guilin University of Electronic \\ Technology, Guilin, Guangxi, China, 541004.
}

Received: October 6, 2020

doi: $10.5539 /$ elt.v13n12p83
Accepted: November 20, 2020

Online Published: November 27, 2020

\begin{abstract}
EFL teaching plays a special and important role in development of a country shouldering the responsibility of development of intercultural competence. EFL teaching in China to some extent cannot fully realize the teaching aims due to its narrowed focus on linguistic objectives more than cultivation of interculturality. Integration of intercultural education into EFL and research of how teachers can be oriented with intercultural teaching pedagogy to conduct suitable activities to develop students' intercultural communicative competence are urgently needed. Inspired by the theories of intercultural language teaching, this paper attempts to revise the instructional pedagogy in College English in China by applying the intercultural teaching with the film as the medium, so as to explore the practical way of integrating intercultural communication competence training with language skills training in teaching practice.
\end{abstract}

Keywords: intercultural language teaching, cultural teaching, cross-cultural critical thinking ability, intercultural competence

\section{Introduction}

Since the 21 st century, the world pattern has appeared the internationalization, the characteristic of globalization. The education must make the new adjustment to meet the challenge.

In such a special era, the academic circles in many countries have realized that foreign language education has a special responsibility and important strategic significance for development of a country. Many Western countries have developed policy based on the conviction that the development of intercultural competencies is an essential feature of school education and that the responsibility for this falls to language education.

China is no exception. The roles of culture teaching and intercultural education in contemporary time are confirmed and emphasized. In this context, new trends and new ideas have been emerging in the field of foreign language education and teaching in China, such as the "renwen huigui", that is "humanistic regression of foreign language education", "foster the language educational function and emphasize cross-cultural competence through foreign language teaching". The birth and research of these ideas have greatly enriched the connotation of foreign language education.

Intercultural language teaching refocuses the goal of teaching and learning by shifting away from a narrower focus on linguistic or communicative competence, and towards a more holistic goal of intercultural competence (Newton, 2010). The 'interculturality' is developed by 'linguistic and cultural competences in respect of each language are modified by knowledge of the other and contribute to intercultural awareness, skills and know-how' (Council of Europe, 2001).

The traditional EFL teaching in China which is focusing mainly language skills is no longer proper for the challenges, and is not conducive to the cultivation of global citizens. Separating language and culture, therefore, can lead to stereotyping and prejudice. As Zhang (2007) points out that intercultural language teaching is not only teaching just a foreign language itself, but to help learners "compare the target culture and other cultures with their own culture, reflect and better understand their own national culture and individual cultural reference 
framework". EFL teachers are now facing the biggest challenges. Unluckily, they are not all well-prepared.

In China, College English has been a compulsory course for non-English majors. In order to cultivate and improve students' comprehensive ability, instructions are always focusing on students' English skills such as listening, speaking, reading and writing, while ignoring the course educational function, let alone cross cultural literacy, cross-cultural adaptation ability training. Obviously, the current teaching practice can't be fully qualified for the cultivation of graduates with cross-cultural awareness.

Teachers are not ready for intercultural language teaching. Chau argued that teachers had very good awareness of intercultural teaching objectives, fairly good understanding of intercultural teaching but rarely conducted intercultural teaching activities in class (Chau, 2019). Zhou (2011) confirmed that teachers did not deal with intercultural integration properly. Intercultural instruction was mainly knowledge focused and teacher-centered. Nguyen (2013) concurrently found that intercultural teaching was accidental, implicit, and topic dependent because they just followed the course books.

\section{Purpose of this Study}

Integration of intercultural education into EFL and research of how teachers can be oriented with intercultural teaching pedagogy to conduct suitable activities to develop students' intercultural communicative competence are urgently needed.

Inspired by the theory of intercultural language teaching, this paper attempts to revise the instruction in College English by applying the intercultural teaching approaches with the film as the medium, so as to explore a practical way of integrating intercultural communication competence training with language skills training in teaching practice.

\section{Inter-cultural language teaching practice: instruction with films as sources}

The teaching design using film as the medium can embed cultural teaching, cultivate students' intercultural literacy and intercultural critical thinking ability. It is necessary for teachers to excavate the material content, integrate teaching resources, scientifically design teaching objectives and contents, and carefully implement each teaching step, so as to achieve targeted and effective teaching.

\section{Re-consider the sources: Films as intercultural teaching sources}

It is possible to envisage a simulation where learners are provided with sources and asked to compare and to analyse documents from their own and the other society (Byram, 1997). Film provides an important representation of cultures and their salient issues. A film provides students with a window to many of the cultural variables that influence management theory and practice but that they may not have personally experienced (Mallinger, 2003). Films can bring the audience into the foreign cultural society, triggering the thinking on the cultural differences, reflecting on their own culture, and developing cultural critical thinking. Films integrate nature and society, culture and history, science and art, religion and morality, ideal and reality. Films are strong in artistry, combines language, music, fine arts and other art forms with various genres, thus considered a shortcut for students to contact and understand the culture of English-speaking countries. Therefore, films are frequently adopted as a cultural teaching tool.

The chosen film should provide several clear examples of contrasting values and the behavioral manifestations that result (Mallinger, 2003). The Proposal, as a romantic comedy, popular among both young and old, is rich for classroom teaching to Chinese students for its exposure of culture differences. Literature review shows that some research papers study pragmatic strategy, assisting audience to better understand and appreciate the charm of film language, some analysis show the cheating language translation, criticism of linguistic analysis, etc. In addition, there are some papers discovering about the study of feminism patriarchal alluding to. However, there is no discussion of taking the film as material for intercultural competence development.

\section{Re-directed Teaching objectives}

At present, the mode of intercultural education in College English courses is relatively backward, and it is difficult to give full play to students' main role in curriculum setting, teaching objectives, teaching content, teaching methods and other aspects, and achieve the ultimate goal of cultivating intercultural competence.

The cultivation of students' cross-cultural knowledge and skills depends on professional and reasonable curriculum setting, teaching content and teaching methods, which emphasize the smooth transformation from theory to practice.

However, College English lessons in China are given much more priority to textbook teaching, highlighting the teaching goals of language skills. On the contrast, culture teaching, intercultural teaching objectives are not clear, 
prominent, and lead to failure to properly guide students to think about the culture behind the language, to analyze cultural conflict problem, to find the crux of the problem, to treat foreign culture with cultural sensitivity, to build the tolerance and the flexibility of dealing with cultural issues. To sum up, the current teaching aim is really ill-fitted for the cultivation of students' cross-cultural competence.

The Council of Europe's Common European Framework of Reference for Languages (2001) discusses the need for the development of general (as opposed to linguistic) competences, including 'intercultural skills and know-how', which comprise:

- the ability to bring the culture of origin and the foreign culture into relation with each other;

- cultural sensitivity and the ability to identify and use a variety of strategies for contact with those from other cultures;

- the capacity to fulfill the role of cultural intermediary between one's own culture and the foreign culture and to deal effectively with intercultural misunderstanding and conflict situations;

- the ability to overcome stereotyped relationships. (pp. 104-5)

Cross-cultural education is necessary for students to get cross-cultural experience to make full preparation for their future study, work and life in the intercultural situation. Taking this instructional plan as an example, the preset teaching objectives can be centered on items from listed above. Teachers should formulate appropriate, feasible and practical teaching objectives according to students' level and teaching content.

\section{Re-constructed Teaching content}

In the current College English teaching in China, there are noticeable deficiencies on teachers' instruction, the interpretation of the cultural content and the activities involving the content. What's more, teachers' understanding of the importance of cultural teaching is inadequate too. The current syllabus advocated is not consistent with the purpose of enhancing intercultural communication by learning a language.

The content of intercultural English teaching focuses on improving students' ability to use English in intercultural context following the "input-noticing-reflection—output-noticing-reflection" pathway displayed below proposed by Liddicoat et al. (2003, p. 20) for developing intercultural competence. This pathway guides learners to discover the less visible aspects of culture in language.

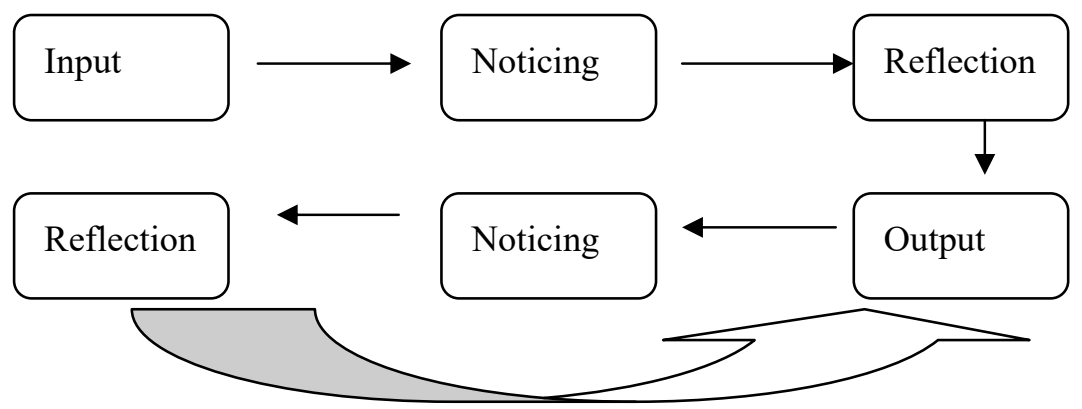

Figure 1. A pathway for developing intercultural competence

Source: Liddicoat, $2002 \mathrm{~b}$

The model presupposes a starting point of exposure to a wide range of authentic texts and sources (including oral, performative, visual and written texts/sources) and/or opportunities for interaction with speakers of the target language. Working from this starting point, learners are encouraged to notice features of the communicative event that are unfamiliar (noticing). Noticing requires learners to draw on their culture-general knowledge, as well as make comparisons between the observed communication and their own. They then discuss the reasons for these features as well as their personal response to them (reflection). Opportunities for communication follow, allowing them to experiment with new forms, expressions or strategies derived from the earlier input (output). Learners then attend to how 'comfortable' these feel and how successful the communication was interpersonally (noticing again).

Effective intercultural teaching needs to take some principles into account, such as exploratory discovery-based learning, comparing and connecting cultures and social interaction. 


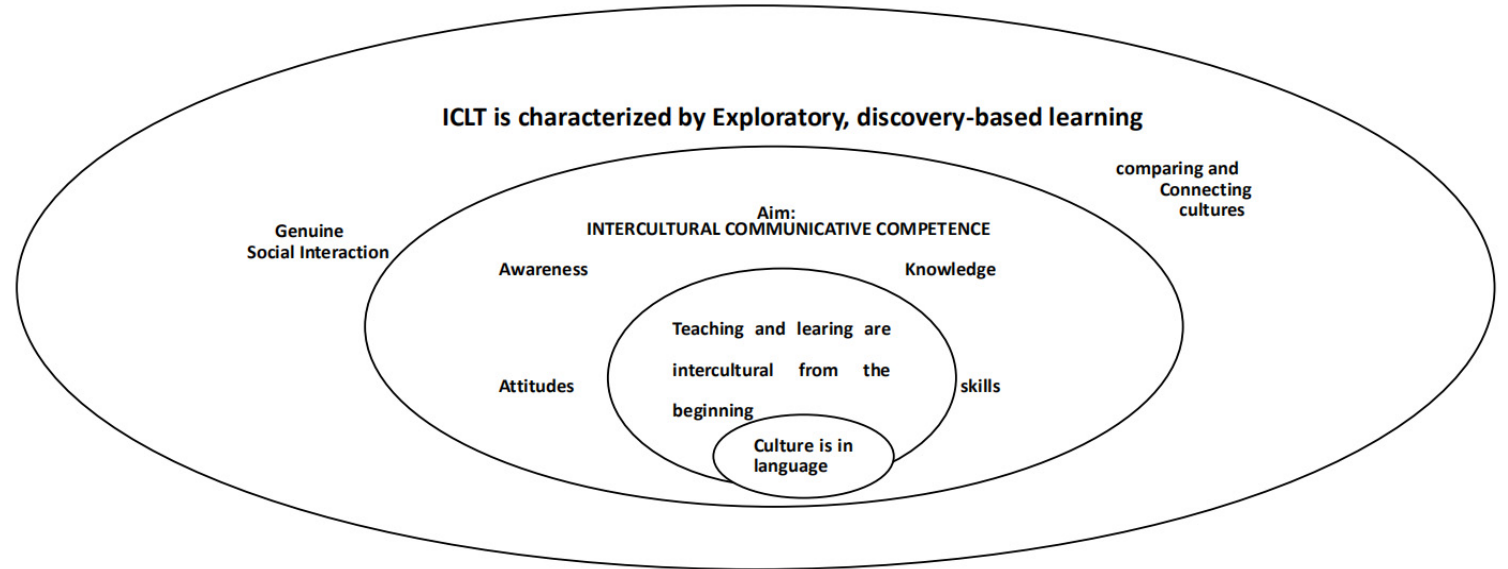

Figure 2. Principles for effective intercultural communicative language teaching and learning (iCLT)

Source: Newton, 2010

In terms of teaching methods, case study and role play are most frequently adopted because of their remarkable training effect in cultural knowledge introduction, intercultural knowledge exploration, cross-cultural contexts practice to guide students to "experience", "practice" and "immerse" in cross-cultural contexts. Hence, through these approaches, EFL teaching objectives of cultivating learners' practical ability of intercultural language communication can be achieved.

Preparing a lesson, surely teacher can prepare 3 types of contents from text background information, text themes, text details and vocabulary teaching. Though, these textbook teaching materials are useful and practical but still lack of eye-catching impressive effect to stimulate students.

Teachers can search other resources to create the cultural learning atmosphere. Movies have particular superiority in terms of content, material, means and context for language learning input as well as cultural study.

An online survey was conducted to check students' feedback and the result shows that learners fed back positively after the film watching as cultural factors are vividly shown in front of them, the culture shock they experienced from the movie is obvious and underestimate. Teachers need to further optimize the teaching resources, break the limitation of textbooks, promote student-centered, improve the level of students' cross-cultural communication awareness and communication.

\section{Re-designed Teaching}

\section{Step 1: Input--Noticing--Cultural introduction}

In College English teaching, it is common to pay more attention to the cultivation of language skills while neglecting the analysis of culture, which is not conducive to the improvement of students' cross-cultural ability and the cultivation of their international literacy.

The teaching objective of this lesson is an unusual film audiovisual lesson. For the time being, language skills training, such as film dubbing and stylistic analysis, etc. are put on the back foot, while cultural contrast, cultural conflict and its resolution are taken as the teaching objectives of this course to cultivate students' intercultural critical thinking ability.

The cross-cultural teaching should not be in the scope of the default, it puts forward more requirements for teachers. The challenges are many but one is really prominent, that is, there is no ready-made reference for the teaching content, teaching outline, in culture teaching in EFL classrooms. Therefore, quality teaching relies more on the teachers' cross-cultural literacy, awareness and instructional ability of cross-cultural teaching.

This teaching process is more than a brief introduction to culture. The content of cultural introduction should be made according to the students' level and teaching syllabus, and it should also be noted that the content of the introduction should be related to the content of the textbook or expand the content of the textbook.

Take the film "The Proposal" for example, such themes as marriage and love appear repeatedly in College English textbook, New Horizon College English ( $3^{\text {rd }}$ Edition), as a common topic. Therefore, the teaching content chosen is expanded and based on the textbook.

When the teacher guides the students, the teaching methods such as asking questions, presenting posters and 
short discussions can be used to conduct the introduction. The pedagogical interventions are as follows.

First, teacher asks:

\begin{tabular}{ll}
\hline 1. Where do you think is a good place to propose? & Input \\
\hline 2. What are the rules for proposing marriage in general? & Noticing \\
\hline
\end{tabular}

Then, poster presentation:

The teacher shows the posters of The Proposal and asks the question.

Compared with the traditional marriage proposal in the traditional marriage custom that a man holding a wedding ring and kneeling down to the woman to propose. Please compare with the scene in the poster that the female kneeling down to propose. Talk about your idea and guess the possible reason.

After that, students discussed and found out something different to the common sense. First, the venue of the proposal is in the busy street. Second, both man and woman are in office suits. Third, the one who is kneeling down to ask the other to marry is the woman. Such a gender inversion for marriage proposal caused the students' expectations for the story.

Then, the teacher briefly introduces the director, actress and actor, and the overall influence of the film.

Next, as an important step of cultural introduction, the whole film is played.

The students have already acquired adequate language ability to understand the scene and plots in the movie. The sumptuous audio-visual feast effectively stimulated the senses and the information processing in the brain, so that they could naturally enter the foreign environment and context of the film and begin the learning process of association, cognition and thinking.

The process of film playing is an important process of cultural input or even cultural immersion, which can not only facilitate the learning of language skills but also achieve the purpose of learning the culture of the target language.

The film directly places the students in the local history, geography, customs, lifestyles, codes of behavior and values, opening up a deep and broad space for cultural and language learning.

\section{Step 2: Reflection--Think about conflicts}

Foreign language learners should be aware of the need to compare, contrast and establish relationships between concepts in their own and the foreign language, including the problems of dysfunction and conflicts (Byram, 1997).

After the video is played, the students are divided into groups to think about three questions, discuss them in groups, and then write the speech outline. The three questions given by the teacher for discussion are:

\begin{tabular}{ll}
\hline 1. One of the scenes in the film that makes you feel most different in culture & Noticing \\
\hline 2. The modern Western concept of love and marriage reflected in the film & Reflection \\
\hline 3. Comparison of Chinese and Western concepts of love and marriage &
\end{tabular}

The design of the problem is not random, but based on the goal of training and learning path. For example, question 1 is consistent with the first item of the teaching objective, that is, it focuses on cultivating students' cross-cultural awareness and sensitivity, and helps them to view, analyze and solve problems from a cross-cultural perspective.

Questions 2 and 3 try to enrich students' cultural knowledge, including their own cultural knowledge and foreign one, also in line with their respect, tolerance, understanding and appreciation of different cultures. When the students are in the process of group discussion, the teacher plays the role of a facilitator of learning, either to join the team, to listen, to assist the summarized key points, or to give guidance, which students benefit from. Students from peer groups exchange ideas on different points of view, complement each other, learn from each other. When the teacher joins as members of the discussion, students are given more concern.

The cultivation of cross-cultural critical thinking ability needs such open topics, discussion ideas and summative language output. The above three discussing questions designed for cross-cultural teaching goal and learning path can comprehensively train students' cross-cultural ability, set examples of summative language ability. More in-depth questions can be raised after completion of these questions to guides the student to continue on in the culture reflection, for example, any other cultural differences in the film shocked them. 
In the discussion section, the design of discussion topics must be based on students' previous knowledge and skills and the discussion should be guided in a well- planned way, so as to further correct students' attitude towards cultural differences, emphasize understanding and avoid stereotypes and prejudices.

For example, question 1 is an open question so students would have talked about many aspects, like costumes in wedding, the hot sexy bachelor party, Teachers need to exercise their own cross-cultural ability and cultural teaching approach to sort out and select an important topic and then guide them for in-depth exploration.

\section{Step 3: Output--Cultural inquiry}

University students seldom have further exploratory learning in some aspects involving the great differences between Chinese and Western cultures in EFL classroom.

This indeed is the common fault of the cross-cultural language teaching in China. Studies on EFL teacher interviews showed that the main reason is that teachers are highly susceptible to the teaching material, the outline syllabus, the impact of the teaching, thus they subconsciously ignore this part of the teaching. Though teachers have formed some cross-cultural teaching idea, but these precious ideas are less involved or related in teaching practice.

Even if there is some involvement, it normally stays at the shallow level of culture knowledge introduction. Those teaching activities that focus on cultivating students' cross-cultural awareness and attitude, and even cross-cultural skills, such as the inquiry activities of cultural contrast, are lack greatly.

As for the questions raised above, the students' answers were varied. Some groups only summarized the phenomenon of cultural differences, for example, the students put forward the differences between Chinese and Western wedding etiquette, and illustrated with examples, such as the differences in wedding venues, ceremonies and costumes.

But when the teacher asked why in the western wedding, the bride wear white, why the wedding is held in the church and so on, some students could not give a further affirmative answer.

At this time, when the teacher gives some reference literature and guides the students to read for answers, the students are interested in the further questions proposed by the teacher. This learning process goes beyond the previous level of "cultural knowledge", and then begins to explore the background information of differences.

For the cross-cultural attitude, it can be considered as a promotion above the knowledge, students should at least neither resist, nor immediately but rashly draw certain conclusions based on personal feelings.

Finally, through reading and searching literature, students found that white was the dominant color in Western weddings to emphasize the reverence for marriage loyalty and purity, and the commitment of church priests and newlyweds was related to religion.

Christianity has always been the most influential religion in the West. It touches every aspect of people's lives. From the moment one is born to the moment one is baptized to the moment one dies, prayer is inseparable from religion, and naturally it has become part of the marriage custom.

Therefore, understanding and answering questions are self-exploration initiated by students under the guidance of teachers, which also strengthens the subjectivity of learning. As a result, students' understanding of cultural phenomena rises from superficial knowledge to deeper understanding.

\section{Step 4: Noticing again---Cultural contrast}

The crucial element of the knowledge dimension is that it should include a comparative method and be related to the development of critical cultural awareness (Byram, 1997).

One of the aims of this teaching step is therefore the development of cultural awareness, that is, 'agradually developing inner sense of the equality of cultures, an increased understanding of your own and other people's cultures, and a positive interest in how cultures both connect and differ' (Tomlinson \& Matsuhara, 2004, p. 7)

This strengthens cross-cultural awareness and sensitivity and helps them to view, analyze and solve problems from a cross-cultural perspective.

To this end, the teacher continued to ask questions:

\begin{tabular}{ll}
\hline 1. The influence of religion, clan and family concept between Chinese and Western & Output \\
marriage customs. & \\
2. What do you think of the popular etiquette in Chinese and Western wedding? & Noticing again \\
\hline
\end{tabular}


For example, teachers carefully observe the students' analysis and presentation of the influence of religion between Chinese and Western marriage customs, provide appropriate guidance and summary, and then inform the students with the help of literature research.

Marriage is completely regarded as an institution created by God, is the eternal agreement between the parties in marriage, and has sacred solemnity. The union of Adam and Eve established the monogamy in Christianity. The church was in the Garden of Eden, and God was the officiating person, which determined that the church wedding was the traditional form of marriage in European and American countries and had legal importance.

Chinese people believe in intangible things, including Buddhism and ancestors, so Chinese people seem to be atheists seemingly, but in fact they are not. Chinese marriage customs are permeated with respect to ancestors and belief in divination and prophecy, but they lack certain fixed procedures and forms.

Also, there are differences in marriage concepts between China and west. Chinese traditionally see marriage more as a way to extend the family line, preserve the family name and strengthen the family, and put the benefit of the family group first. In the West, marriage is more regarded as the union of lovers and more concerned with personal happiness and willingness.

These comparisons need to be fully summarized by students themselves. Comparison is output of critical thinking activities, rather than the infusion of knowledge. Such a learning process enables the students to form an attitude of calm in dealing with problems in cross-cultural settings.

Cultural contrast is not an emphasis on confrontation or to distinguish the better from the worse. Its main purpose is to properly guide students to think about the culture behind the language, analyze the problem of cultural conflicts, encourage students to find the crux of the problem, cultivate students' sensitivity to cultural differences, tolerance to foreign cultures and flexibility in dealing with cultural issues.

For example, wearing white in Chinese wedding was a taboo, because white was thought to be unlucky and frequently used in funerals. Students need to find the crux of the cultural conflict, cultivate the ability to deal with cultural issues flexibly.

\section{Step 5: Reflection---Skill training}

Teachers assign tasks:

1. Interview your parents and grandparents about their wedding and explain how you will plan yours.

2. Explain to foreign tourists the evolution of modern Chinese marriage customs.

\section{Reflection}

3. Why is a mixed type wedding that contains both Chinese and Western elements popular in China? Predict the future trend of weddings in China.

The cultivation of intercultural communicative competence under the framework of EFL teaching not only emphasizes the extensional ability to communicate with different cultural groups, but also gives equal importance to the learners' association between mother tongue and culture and the ability of introspection. Learners need to become aware of what is meant by culture, and what aspects of their behaviour and language use are culturally specific. Thus intercultural teaching and learning require self-reflection, through which learners come to understand how their culture influences their use of language, and how their communicative interactions reflect their culture (Tomlinson, 2004).

Therefore, it is necessary for teachers to guide students to reflect and introspect Chinese culture in EFL courses. Foreign language courses should be duty-bound to carry forward the excellent traditional Chinese culture, cultivate cultural confidence and cultivate patriotism.

The first question is a descriptive question, which requires students to describe the evolution of China's marriage customs of the past three generations mainly by introduction with rich traditional Chinese cultural deposits.

Question 2 is also of this category, but a little more demanding. It challenges students' thinking and language ability. Students can basically form opinions and express themselves in positive words.

Students responses question 3 with "cultural dialogue", "negotiation of cultures between China and west", "fancy education received by new generation", and "the China Opening-up Policy and social progress" etc, teachers continue to convey that the reason of modern marriage customs presents in mixed elements of Chinese and western wedding cultures lies in the fact that Chinese Youth is absorbing essence of both cultures, bringing romantic and solemn, contracted and fashionable, thrift and solemn atmosphere in to their weddings. This also showed the young people today already preserve traditional Chinese style, and selectively accept western culture, thus present a correct cultural attitude. 


\section{Conclusion}

After the lesson, most of the students reviewed, "more enjoyable than writing lessons", "be mobilized to speak English with rich vocabulary and sentence pattern", and "have a lot to say on the topic", "a big challenge for English skills", "what's next" ,"would like to take another similar class".

Crawford and McLaren recommend that appropriate language is taught to meet the needs of the students in such exploration, that is, their communicative needs, not necessarily the language which the textbooks tell them to learn and use (Crawford, 2003).This cultural teaching lesson, which seems to be separated from textbooks and mediated by movies, is actually the resultant force of students' comprehensive competence cultivation and the ultimate reflection of teachers' teaching ability.

A part of this pedagogical requirement is a serious regular preparation for classes by teachers and students, flexible teachers exert, also provide students dialectical thinking space, allow the students to realize that cross-cultural communication is not to give up their own culture to follow or go along with the other party's cultural practices, but in the case of coordination to understand each other, respect each other's culture and effectively achieve the purpose of cross-cultural communication. In addition, the teacher must "together with students, engage in 'cultural exploration"” (Crawford, 2003, p. 153), guides students actively, not biased for cultural differences in attitude, discrimination or stereotypes, eventually improve on cultural skills, able to face up to the foreign culture and its framework, and reflect on its own culture and framework, form a critical cultural awareness.

\section{Reference}

Byram, M. (1997). Teaching and assessing intercultural communicative competence. Clevedon; Philadelphia: Multilingual Matters.

Chau, T. H. H., \& Truong, V. (2019). The Integration of Intercultural Education into Teaching English: What Vietnamese Teachers Do and Say. International Journal of Instruction, 12(1), 441-456. https://doi.org/10.29333/iji.2019.12129a

Council of Europe. (2001). Common European framework of reference for languages. Cambridge: Cambridge University Press.

Crawford, L. M., \& McLaren, P. (2003). A critical perspective on culture in the second language classroom. In D. L. Lange \& R. M. Paige (Eds.), Perspectives on culture in second language learning (pp. 127-157). Greenwich, Connecticut: Information Age Publishing.

Liddicoat, A. J. (2002b). Static and dynamic views of cultural and intercultural languages acquisition. Babel, $36(3), 4-11$.

Mallinger, Rossy. (2003). Film as a lens for teaching culture: Balancing concepts, ambiguity, and paradox. Journal of Management Education, X27(5), 608-624. https://doi.org/10.1177/1052562903252642

Newton, J., Yates, E., Shearn, S., \& Nowitzki, W. (2010). Intercultural communicative language teaching: implications for effective teaching and learning. (pp. 1-90). Report to the Ministry of Education. Retrieved from http://www.educationcounts.govt.nz/publications/curriculum/76637/introduction

Nguyen, T. L. (2013). Integrating culture into Vietnamese university EFL teaching: A critical ethnography study. Electronic Theses and Dissertations. Auckland University of Technology, New Zealand. Retrieved from http://hdl.handle.net/10292/5975

Tomlinson, B., \& Matsuhara, H. (2004). Developing cultural awareness: Integrating culture into a language course. Modern English Teacher, 13(1), 1-7.

Zhang, H. (2007). Cross-cultural Foreign Language Teaching. Shanghai: Shanghai Foreign Language Education Press.

Zhou, Y. (2011). A study of Chinese university EFL teachers and their intercultural competence teaching. Electronic Theses and Dissertations. University of Winsor, Canada. https://doi.org/10.1057/9780230299481_7

\section{Copyrights}

Copyright for this article is retained by the author(s), with first publication rights granted to the journal.

This is an open-access article distributed under the terms and conditions of the Creative Commons Attribution license (http://creativecommons.org/licenses/by/4.0/). 